\title{
Linear Correlation Analysis of Zymoseptoria tritici Aggressiveness with In Vitro Growth Rate
}

\author{
Fangfang Zhan, Yiekun Xie, Wen Zhu, Danli Sun, Bruce A. McDonald, and Jiasui Zhan
}

First, second, third, and fourth authors: Fujian Key Lab of Plant Virology, Institute of Plant Virology, Fujian Agriculture and Forestry University, Fuzhou, 350002, China; fifth author: Plant Pathology Group, Institute of Integrative Biology, ETH Zurich, LFW, Zurich, CH-8092, Switzerland; and sixth author: Key Lab for Biopesticide and Chemical Biology, Ministry of Education, Fujian Agriculture and Forestry University, Fuzhou.

Accepted for publication 23 June 2016.

\begin{abstract}
Zhan, F., Xie, Y., Zhu, W., Sun, D., McDonald, B. A., and Zhan, J. 2016. Linear correlation analysis of Zymoseptoria tritici aggressiveness with in vitro growth rate. Phytopathology 106:1255-1261.

Zymoseptoria tritici is a globally distributed plant-pathogenic fungus causing Septoria tritici blotch of wheat. In this study, the in vitro growth rates and aggressiveness of 141 genetically distinct isolates sampled from four wheat fields on three continents were assessed to determine the association of

these two ecological parameters. Aggressiveness was assessed on two spring wheat cultivars ('Toronit' and 'Greina') in a greenhouse using percentages of leaf area covered by lesions and pycnidia. We found a positive correlation between aggressiveness of pathogen strains on the two cultivars, consistent with a quantitative and host-nonspecific interaction in this pathosystem. We also found a positive correlation between aggressiveness and average growth rate at two temperatures, suggesting that in vitro pathogen growth rate may make a significant contribution to pathogen aggressiveness.
\end{abstract}

Gaining greater insight into host-pathogen interactions is of primary importance both to understand the evolution of pathogens and to develop sustainable disease management strategies (Zhan et al. 2014, 2015). In plant pathology, host-pathogen interactions are often divided into two major categories: qualitative interactions that depend on compatible or incompatible relationships between hosts and pathogens and are supported by the gene-for-gene model (Pariaud et al. 2009), and quantitative interactions that emphasize the continuous variations in disease development resulting from interactions among multiple genes that contribute minor but additive effects (Makhdoomi et al. 2015; Zhan et al. 2007b). Historically, plant pathologists have paid most attention to qualitative host-pathogen interactions, primarily due to the widespread and effective application of major resistance genes in plant disease management (Lannou 2012). In contrast, the quantitative aspects of host-pathogen interactions remain largely understudied, though interest in quantitative resistance has increased over the last two decades, largely as a result of concerns about agricultural sustainability (Zhan et al. 2014, 2015). Furthermore, both types of interaction are intertwined in many plant-pathogen associations. For example, the evolution of biotrophic pathogens is expected to involve two inseparable steps: a gain in ability to evade host defensive systems via mutations in effector genes (Poland et al. 2009) followed by a series of compensatory mutations to counteract the negative effects of the effector mutation, leading to an increase in pathogen fitness that is reflected by an increase in disease on its host (McConnell et al. 2008; Sokurenko et al. 1999).

Aggressiveness, here defined as quantitative variation in pathogenicity induced by a pathogen strain on its host (Zhan and McDonald 2013), is an important parameter for measuring the quantitative interaction between hosts and pathogens. It can be dissected into

Corresponding author: J. Zhan; E-mail address: jiasui.zhan@fafu.edu.cn

*The $\boldsymbol{e}$-Xtra logo stands for "electronic extra" and indicates that two supplementary figures and one supplementary table are published online.

http://dx.doi.org/10.1094/PHYTO-12-15-0338-R

(C) 2016 The American Phytopathological Society several components, including infection efficiency, latent period, lesion size, lesion growth rate, sporulation capacity, and pycnidia density (Caffier et al. 2010; Montarry et al. 2006). However, these aggressiveness components are highly environment-dependent and can be affected by climatic variables, host genetics, and the physiological status of both pathogen and host (Lannou 2012; Pariaud et al. 2012). Pathogen aggressiveness is usually measured in greenhouses where humidity, light, and temperature are regulated (Li et al. 2009; Malbrán et al. 2012; Montarry et al. 2008; Novo et al. 2006). Evolutionary studies of quantitative host-pathogen interactions require large sample sizes involving hundreds of pathogen strains (Talas et al. 2016; Yang et al. 2013) coupled with many replications to ensure reliable estimates of aggressiveness, features that make quantitative assessments of aggressiveness not only laborious and time consuming but also technically challenging. Most importantly, for plant pathosystems involving both quantitative and qualitative resistances such as potato late blight (Zhu et al. 2015 ), in planta assays of aggressiveness require prior knowledge of the resistance structure in the cultivars. Only universally susceptible cultivars can be used to obtain an unbiased measure of pathogen aggressiveness. Otherwise, null measurement of aggressiveness in isolates may result from their lack of virulence factors to overcome host defense responses (Bari and Jones 2009; Dangl and Jones 2001).

In vitro growth rate, defined as the slope of natural log-transformed biological data (biomass, body size, and so on) in the exponential phase of growth over time, is an intrinsic property of cellular fitness and an important biological parameter widely used in evolutionary biology, functional genomics, and systems biology studies of species to address many crucial questions (Blomberg 2011; Pringle and Taylor 2002). In plant pathology, in vitro growth rate is often determined by measuring the growth of pathogen colonies on agar plates over time (Alker et al. 2001; Antal et al. 2000). The development of automated digital image analysis technologies (Lendenmann et al. 2014) enabled rapid and accurate measurement of growth rates of pathogen colonies using image analysis software.

Whether in vitro growth rate can be used as an indicator of aggressiveness in quantitative host-pathogen interaction is hotly 
debated in plant pathology and may depend on the particular pathosystem under investigation. For example, pathogen strains that grow faster also produce more disease in the plant pathosystems Ulmus procera-Ophiostoma ulmi (Brasier and Webber 1987), Juglans sp.-Gnomonia leptostyla (Belisario et al. 2008), Cakile maritime-Alternaria brassicicola (Thrall et al. 2005), and Acacia mearnsii-Ceratocystis albifundus (Lee et al. 2015) but no correlation was found for wheat-Gaeumannomyces graminis (Irzykowska and Bocianowski 2008) or wheat-Microdochium nivale (Brennan et al. 2003). This inconsistency in the association between aggressiveness and in vitro growth rate can exist even within the same host-pathogen system. For example, in the human-malaria system, the correlation between virulence and multiplication rate of Plasmodium falciparum was positive in isolates from Asia (Chotivanich et al. 2000) but negative in isolates from Africa (Deans et al. 2006). This variation in outcomes of association analysis may reflect differences in immunity of hosts, as discussed in the previous section, or in density and nutritive status of hosts and pathogens, regulatory mechanisms for pathogen invasiveness in particular host-pathogen interactions, or the quality and quantity of phytotoxins that pathogens produce (Deans et al. 2006; Meyer et al. 2010).

Septoria tritici blotch (STB), caused by the haploid ascomycete Zymoseptoria tritici (formerly Mycosphaerella graminicola), is the most economically damaging foliar disease of wheat in Europe (Jorgensen et al. 2014; O'Driscoll et al. 2014) and is an important wheat pathogen in many parts of the world (Allioui et al. 2014; do Amaral et al. 2012). It can reduce wheat yields by 30 to $50 \%$ (Goodwin et al. 2011) and, therefore, can be considered a threat to global food security (Sidhu et al. 2015). A quantitative interaction appears to dominate in this pathosystem but qualitative interactions also exist, as indicated by significant interactions found in the analysis of variance (ANOVA) in disease severity for some combinations of pathogen and host genotypes (Kema et al. 1996; Mundt et al. 1995). Z. tritici isolates vary tremendously in aggressiveness both within and among populations (Ahmed et al. 1996; Zhan et al. 2002). Higher aggressiveness is expected to be selected when the pathogen populations are challenged by quantitatively resistant hosts, leading to erosion in quantitative resistance, as observed in 'Madsen' wheat in Oregon (Mundt et al. 2002). Both percentage of leaf area covered by lesions (PLACL) and percentage of leaf area covered by pycnidia (PLACP) have been used to quantify the aggressiveness of $Z$. tritici (Chartrain et al. 2004a; Cowger and Mundt 2002; Morais et al. 2016; Zhan et al. 2007a). Accurate measures of pycnidial size and density may provide a new and highly relevant estimate of pathogen reproduction that reflects epidemic potential as well as differences in aggressiveness among $Z$. tritici isolates (Stewart and McDonald 2014). Most researchers and breeders use PLACL as their primary measurement of disease severity because PLACP is more difficult to measure and pycnidia development is highly dependent on relative humidity (Kema et al. 1996).

The objective of this study was to investigate the correlation of in vitro growth rate and the expression of pathogen aggressiveness in $Z$. tritici. To achieve this objective, we conducted a correlation analysis of PLACL and PLACP on two wheat cultivars with in vitro growth rates at two temperatures using a global collection of $141 \mathrm{Z}$. tritici isolates sampled from four wheat fields on three continents.

\section{MATERIALS AND METHODS}

Origin of pathogen isolates. The 141 isolates used in this study were chosen from our worldwide collections of $Z$. tritici to represent a wide geographical distribution (Zhan et al. 2003), including Australia, Israel, Switzerland, and the United States, as described previously (Zhan et al. 2005; Zhan and McDonald 2011). These isolates have been stored on silica gel at $-80^{\circ} \mathrm{C}$ since their collection. Previous analyses with seven restriction fragment length polymorphism loci and two DNA fingerprints showed that each of the isolates had a unique genotype (Linde et al. 2002; Zhan et al. 2003).

Measuring pathogen aggressiveness. The aggressiveness of each isolate was determined on two Swiss spring wheat cultivars ('Toronit' and 'Greina') in a greenhouse setting (Yang et al. 2013; Zhan and McDonald 2005). Toronit was moderately resistant to $Z$. tritici and is believed to express nonspecific, quantitative resistance whereas Greina was very susceptible. Plastic pots $(10 \mathrm{~cm}$ in diameter) filled with Ricoter garden soil (Ricoter Erdaufbereitung AG) were sown with 10 seeds of either Toronit or Greina and maintained in greenhouse chambers for 21 days under controlled climatic conditions of $60 \%$ relative humidity (RH) and $20^{\circ} \mathrm{C}$ during a 16-h light period with a continuous supplementation of $50 \mathrm{kLux}$ fluorescent light, and $40 \% \mathrm{RH}$ and $16^{\circ} \mathrm{C}$ during $8 \mathrm{~h}$ of darkness. The plastic pots were arranged according to a completely randomized design with five replicates (i.e., five pots for each isolate-cultivar combination).

To prepare inoculum, fungal isolates taken from silica gel longterm storage were placed on yeast maltose agar plates amended with kanamycin at $50 \mathrm{mg} \mathrm{liter}^{-1}$ and maintained at $20^{\circ} \mathrm{C}$ for 7 days. Blastospores formed on the plates were transferred using an inoculation loop into sterile flasks containing $50 \mathrm{ml}$ of yeast sucrose broth (YSB) (sucrose at $10 \mathrm{~g} /$ liter and yeast extract at $10 \mathrm{~g} / \mathrm{liter}$ )

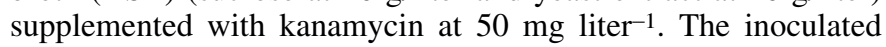
flasks were placed at $20^{\circ} \mathrm{C}$ with continuous shaking for a week. Spore suspensions were adjusted to a concentration of $5 \times 10^{6}$ spores $/ \mathrm{ml}$ on the day of inoculation using a hemocytometer. Inoculations of the wheat seedlings were carried out at 21 days after sowing, at approximately growth stage 11 (Zadoks et al. 1974). Seedlings in each pot were thinned according to their growth status (e.g., based on their height and vigor) to keep the five most uniform plants and then inoculated with $50 \mathrm{ml}$ of the calibrated spore suspension. The inoculated seedlings were kept in greenhouse chambers at $100 \% \mathrm{RH}$ and $21^{\circ} \mathrm{C}$ for 2 days before the chambers were returned to preinoculation conditions. New leaves forming after inoculation were removed at 3-day intervals. Previous studies indicated that $Z$. tritici usually requires approximately 3 weeks to complete an infection cycle (Shaw and Royle 1989; Zhan et al. 1998). Strain aggressiveness was measured at 22 days after inoculation. Approximately 8 to 10 infected leaves were collected from each pot for this measurement by mounting the wheat leaves onto blue paper sheets and photographing them with a digital camera. All inoculations and aggressiveness assessments were completed in a single day to minimize environmental variance among treatments (Yang et al. 2013). The aggressiveness of the fungal isolates was measured as the PLACL and PLACP. PLACL, PLACP, and colony sizes (areas) on petri plates were measured using the image analysis software ASSESS (Lamari 2002).

Measuring pathogen in vitro growth rate. The isolates were retrieved from long-term storage and grown on potato dextrose agar (PDA) (potato dextrose at $24 \mathrm{~g} /$ liter, agar at $12 \mathrm{~g} /$ liter, and kanamycin at $50 \mathrm{mg}$ /liter) petri plates for 1 week at $18^{\circ} \mathrm{C}$. Blastospores from each isolate were transferred to a sterile $50-\mathrm{ml}$ Falcon tube containing $30 \mathrm{ml}$ of YSB. The inoculated Falcon tubes were placed at $18^{\circ} \mathrm{C}$ and shaken continuously at $140 \mathrm{rpm}$ for 5 days. On the sixth day, fungal spores were harvested and diluted to a concentration of 100 spores/ $\mu$ l using a hemocytometer. Colonies were formed by placing a $3-\mu l$ drop of the calibrated spore suspension onto 9-cm PDA petri plates. Each plate contained two colonies of the same fungal isolate. All isolates were replicated across four different plates. Two of the plates, representing two replicates, were kept in an incubator set to $15^{\circ} \mathrm{C}$ after inoculation while the other two plates were kept in an incubator set to $22^{\circ} \mathrm{C}$. The plates in each incubator were arranged using a completely randomized design (CRD). Wheat is grown over a wide range of environments globally, and these two temperatures were chosen to represent average temperatures that might be experienced by the pathogen in cool climates and warm climates. Though experiment units are 
not arranged according to "block", CRD has been widely used in biological, engineering, and social studies when experimental conditions can be controlled more easily, such as in the laboratory (Ott 1992). The entire inoculation procedure was conducted by one person during the course of a single day. Colonies from each isolate were photographed through the lid of the petri dish at 10, 13, 17, 21, and 24 days after inoculation by the same person with a digital camera (Zhan and McDonald 2011). The in vitro growth rate for each isolate at each temperature was estimated using an exponential model (Bates and Watts 1988) based on the areas of individual colonies at each point in time (Zhan and McDonald 2011).

Statistical analyses. The differences in PLACL or PLACP on Toronit and Greina were evaluated using Fisher's least significant difference (LSD). LSD was also used to compare isolate growth rates under different temperatures. In these evaluations, phenotypic variance in PLACL, PLACP, or growth rate was partitioned into sources attributable to isolate (I, random effect), cultivar or temperature $(\mathrm{H}$, fixed effect), replicate $(\mathrm{R}$, random effect), and isolate-cultivar (or temperature) interaction (I-H) using the SAS general linear model procedure (SAS Institute 1990) according to the model $\mathrm{Y}_{\mathrm{ihr}}=\mathrm{M}+\mathrm{I}+\mathrm{H}+\mathrm{R}+\mathrm{I}-\mathrm{H}+\mathrm{E}_{\mathrm{ihr}}$, where $\mathrm{Y}_{\mathrm{ihr}}$ is the observed PLACL, PLACP, or in vitro growth rate for isolate I in
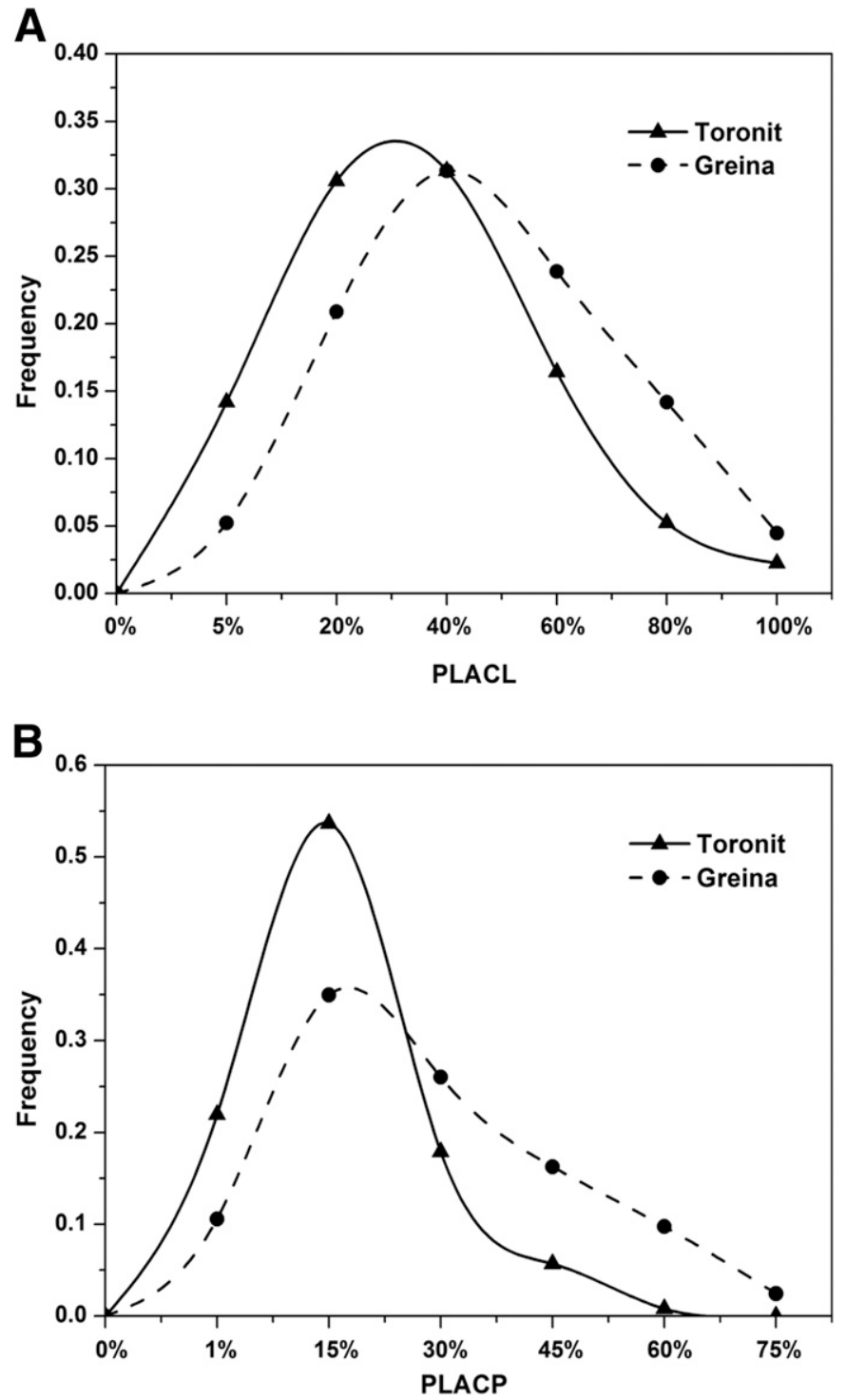

Fig. 1. Frequency distribution of aggressiveness on two wheat cultivars in 141 Zymoseptoria tritici isolates: A, percentage of leaf area covered by lesions (PLACL) and $\mathbf{B}$, percentage of leaf area covered by pycnidia (PLACP). cultivar (or temperature) $\mathrm{H}$ and replicate $\mathrm{R}$; $\mathrm{M}$ indicates the overall mean; and $\mathrm{E}_{\mathrm{ihr}}$ is the experimental error. ANOVA and LSD were performed following square-root transformation of PLACL and PLACP. Exploratory data analysis indicated that transformed data fit better to the model. Square-root-transformed PLACL and PLACP datasets were used to evaluate associations among parameters based on Pearson's correlation analysis (Ott 1992).

\section{RESULTS}

Variation and correlation of pathogen aggressiveness to different cultivars. All Z. tritici isolates induced typical STB symptoms on the two cultivars, with aggressiveness on the two cultivars showing a wide and continuous distribution (Fig. 1). Aggressiveness of the isolates measured using PLACL ranged from 1 to $90 \%$, with an average of $26 \%$, on the moderately resistant Toronit and from 2 to $90 \%$, with an average of $37 \%$, on the susceptible Greina. Aggressiveness of the isolates measured using PLACP ranged from 0 to $50 \%$, with an average of $10 \%$, on Toronit and from 0 to $71 \%$, with an average of $22 \%$, on Greina.

Both the isolate and cultivar components of variance contributed significantly $(P<0.0001)$ to PLACL and PLACP (Table 1). Though isolate-cultivar interactions also contributed significantly to PLACL and PLACP, on average, pathogen isolates induced more disease on Greina than on Toronit (Fig. 2). The aggressiveness measures for each isolate on each cultivar were correlated as

TABLE 1. Analysis of variance for aggressiveness and intrinsic growth rate among 141 Zymoseptoria tritici isolates sampled from four wheat fields in Australia, Israel, Switzerland, and the United States

\begin{tabular}{llrrc}
\hline Parameter & \multicolumn{1}{c}{ Source } & DF & $F$ value & $P$ \\
\hline PLACL & Isolates & 132 & 21.13 & $<0.0001$ \\
& Cultivar & 1 & 234.38 & $<0.0001$ \\
& Isolate-cultivar & 132 & 7.33 & $<0.0001$ \\
& Error & 2074 & $\ldots$ & $\ldots$ \\
PLACP & Isolates & 122 & 13.20 & $<0.0001$ \\
& Cultivar & 1 & 388.24 & $<0.0001$ \\
& Isolate-cultivar & 122 & 7.51 & $<0.0001$ \\
& Error & 1841 & $\ldots$ & $\ldots$ \\
Growth rate & Isolates & 122 & 15.42 & $<0.0001$ \\
& Temperature & 1 & 308.80 & $<0.0001$ \\
& Isolate-temperature & 122 & 3.29 & $<0.0001$ \\
& Error & 246 & $\ldots$ & $\ldots$ \\
\hline
\end{tabular}

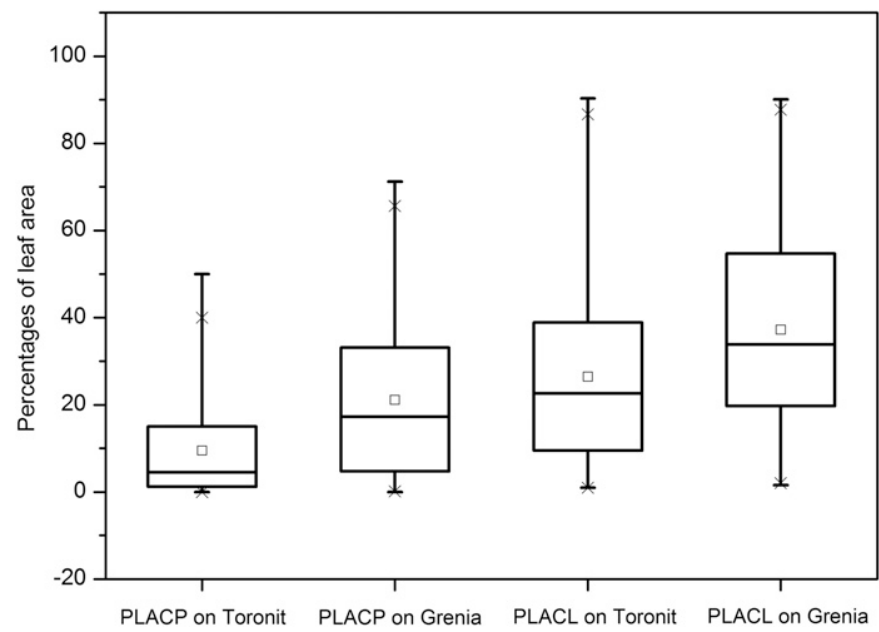

Fig. 2. Boxplots of the aggressiveness of the 141 Zymoseptoria tritici isolate on Greina and Toronit wheat. The horizontal lines in the box denote the 25th, 50th, and 75th percentile values. The " $x$ " marks denote the 99th and 1th percentile values. Error bars denote the maximum and minimum value. The square symbol in the box denotes the mean value. 
indicated by the highly significant correlations between PLACL ( $r=$ $0.51, P<0.0001)$ (Fig. 3A) and PLACP $(r=0.34, P<0.0001)$ (Fig. $3 \mathrm{~B}$ ). In addition, the two measures of aggressiveness (PLACL and PLACP) for each isolate were positively correlated on both Toronit $(r=0.65, P<0.0001)$ (Fig. 4A) and Greina $(r=0.59, P<0.0001)$ (Fig. 4B).

Variation and correlation of pathogen growth under different temperatures. At $15^{\circ} \mathrm{C}$, the in vitro growth rate for the $141 \mathrm{Z}$. tritici isolates ranged from 0.049 to $0.124 \mathrm{~cm}^{2} /$ day, with an average of $0.091 \mathrm{~cm}^{2} /$ day. At $22^{\circ} \mathrm{C}$, the in vitro growth rate ranged from 0.057 to $0.150 \mathrm{~cm}^{2} /$ day, with an average of $0.102 \mathrm{~cm}^{2} /$ day. Like PLACL and PLACP, isolate, temperature, and isolate-temperature interaction all contributed significantly $(P<0.0001)$ to the in vitro growth rate variance (Table 1). On average, isolates grew significantly faster at 22 than at $15^{\circ} \mathrm{C}$ (data not shown) and the in vitro growth rates of isolates (Supplementary Table S1) were positively and significantly correlated $(r=0.62, P<0.0001)$ (Fig. 5) at the two temperatures.

Correlation between pathogen aggressiveness and in vitro growth rate. Aggressiveness and in vitro growth rate for the 141
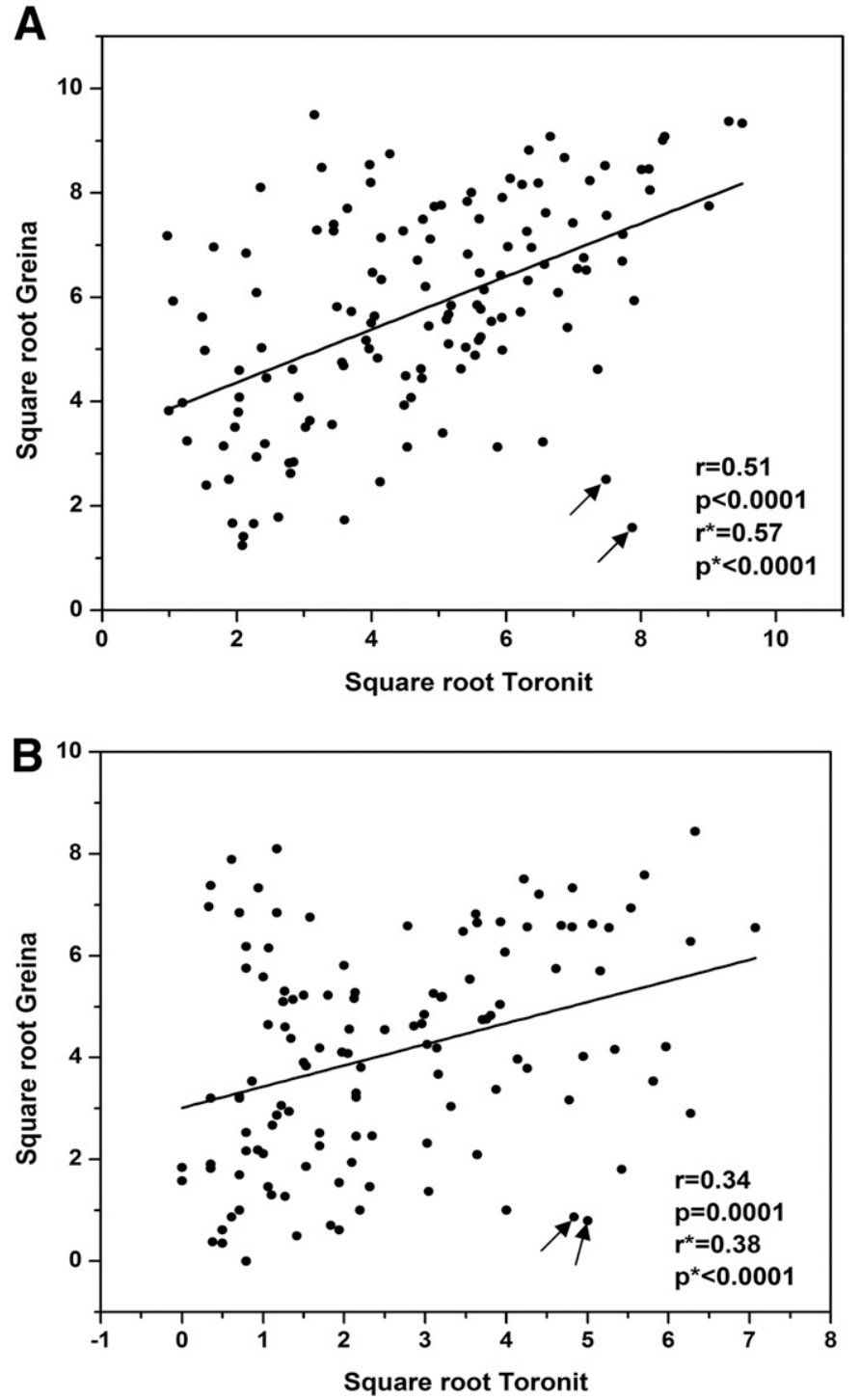

Fig. 3. Correlation of measures of aggressiveness for 141 global Zymoseptoria tritici isolates on Toronit and Greina wheat. Outliers are marked by arrows. Correlation coefficients and associated $P$ values after removing outliers are marked by asterisks. A, Percentage of leaf area covered by lesions (PLACL) and $\mathbf{B}$, percentage of leaf area covered by pycnidia (PLACP).
Z. tritici isolates were positively correlated (Fig. 6; Supplementary Figs. S1 and S2). The correlation coefficient between average of in vitro growth rate at 15 and $22^{\circ} \mathrm{C}$ and average of PLACP induced on Greina and Toronit was 0.32 and the correlation coefficient between average of in vitro growth rate at 15 and $22^{\circ} \mathrm{C}$ and average of PLACL induced on Greina and Toronit was 0.27 . Both of these correlation coefficients were highly significant $(P \leq 0.01)$ (Fig. 6).

\section{DISCUSSION}

Quantitative host-pathogen interactions are usually assumed to be controlled by many genes, with each contributing a small but additive effect to the expression of host and pathogen characteristics such as aggressiveness and resistance (Irzykowska and Bocianowski 2008; Weber et al. 2005). Consequently, the corresponding host and pathogen characteristics are expected to display a continuous variation resulting from the segregation of additive alleles at many interacting loci (Irzykowska et al. 2001). The wide, quantitative variation in disease severity induced by $Z$. tritici in the current and
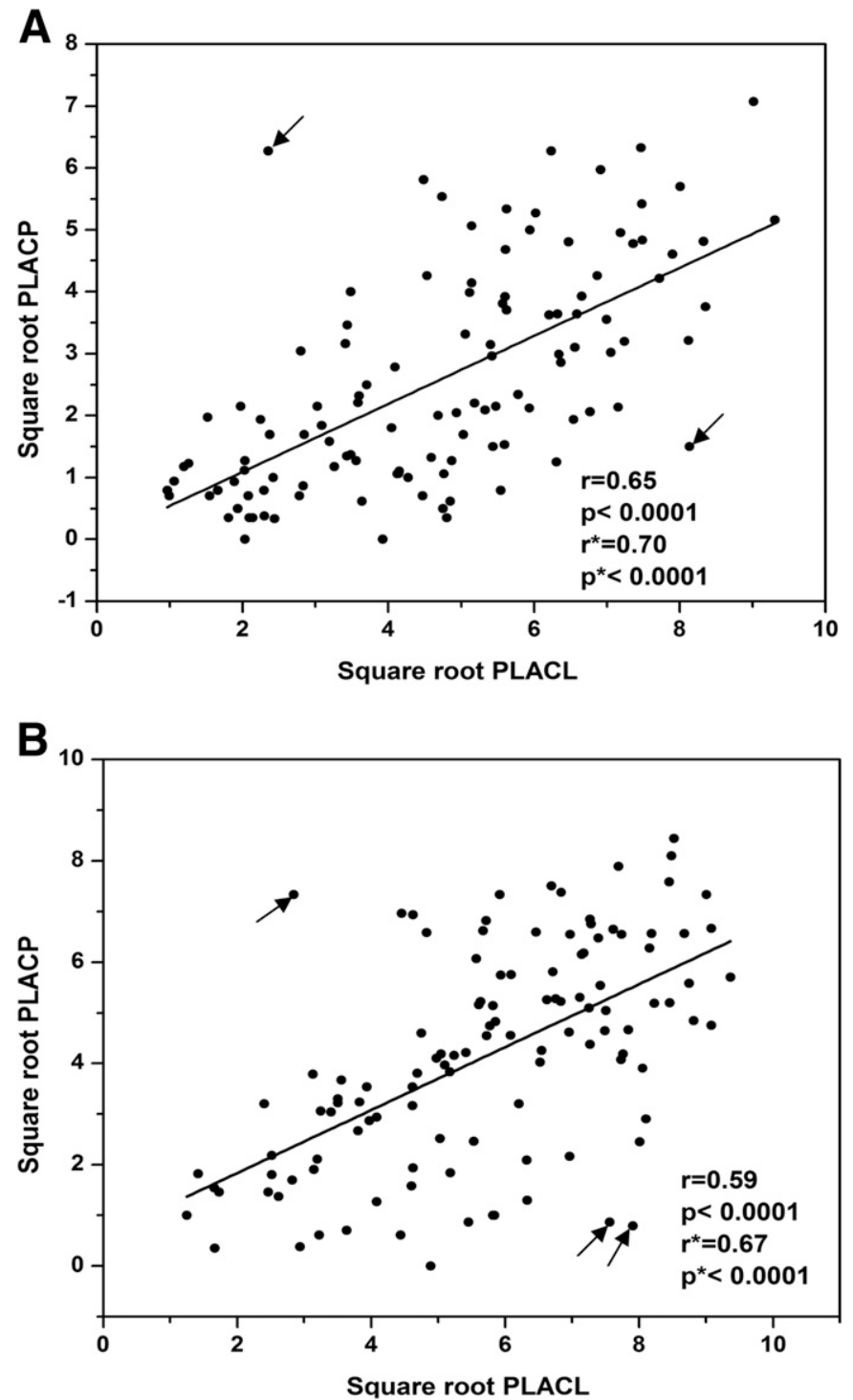

Fig. 4. Correlation between percentages of leaf area covered by lesions (PLACL) and pycnidia (PLACP) on two wheat cultivars (A, Toronit and B, Greina) for 141 Zymoseptoria tritici isolates. Outliers are marked by arrows. Correlation coefficients and associated $P$ values after removing outliers are marked by asterisks. 
previous studies (Chartrain et al. 2004b; Czembor et al. 2011) is consistent with these expectations, indicating a mainly quantitative basis for host-pathogen interaction in the wheat-Z. tritici system. For plant pathogens, it is commonly believed that quantitative host-pathogen interactions are host nonspecific (Hu et al. 2008); that is, the relative amount (and corresponding ranking) of disease induced by a pathogen strain will not be affected by the host genotype. However, some recent studies (Marcel et al. 2008) showed that quantitative host resistance can be strain specific. In our experiments, the majority of $Z$. tritici isolates formed smaller lesions and fewer pycnidia on the moderately resistant Toronit wheat than on the susceptible Greina. The nonspecific nature of the host-pathogen interaction in this experiment was supported by a positive and significant correlation between disease symptoms produced by $Z$. tritici isolates on the two cultivars (Fig. 3). This strong correlation in aggressiveness on different cultivars led us to merge the two datasets to analyze the association between aggressiveness and in vitro growth rate (Gomez and Gomez 1976). However, the significant isolate-cultivar interaction found for disease severity (Table 1) and the fact that some Z. tritici strains caused significantly higher disease on one cultivar than the other (Zhan et al. 2007b) suggests that some degree of host specificity may also exist in our experiment. Some of these data were identified as outliers in Pearson's analysis. It has been reported that many susceptible cultivars contain defeated qualitative resistance (LozoyaSaldaña 2011) and the observed pattern of host-specificity in our experiment may be explained, in part, by residual effects of defeated qualitative resistance in Greina.

In this study, both PLACL and PLACP were used to measure the aggressiveness of $Z$. tritici. The positive correlation found between these two measurements of pathogen aggressiveness (Fig. 4) (Brown et al. 2001; Krenz et al. 2008; Radecka-Janusik and Czembor, 2014) suggests that, as lesion size increases, the leaf area covered by pycnidia also increases, even though these two aggressiveness components may be affected by different evolutionary processes (Zhan et al. 2005). For many fungal pathogens, necrotic lesions are needed for pycnidia formation (Kelm et al. 2012). As a result, the significantly positive association between PLACL and PLACP observed in this study was not unexpected, though the two parameters were not highly associated, as indicated by the relatively small correlation coefficients (Fig. 4). A similar moderate correlation $(r=0.37, P<0.001)$ was observed in a quantitative trait

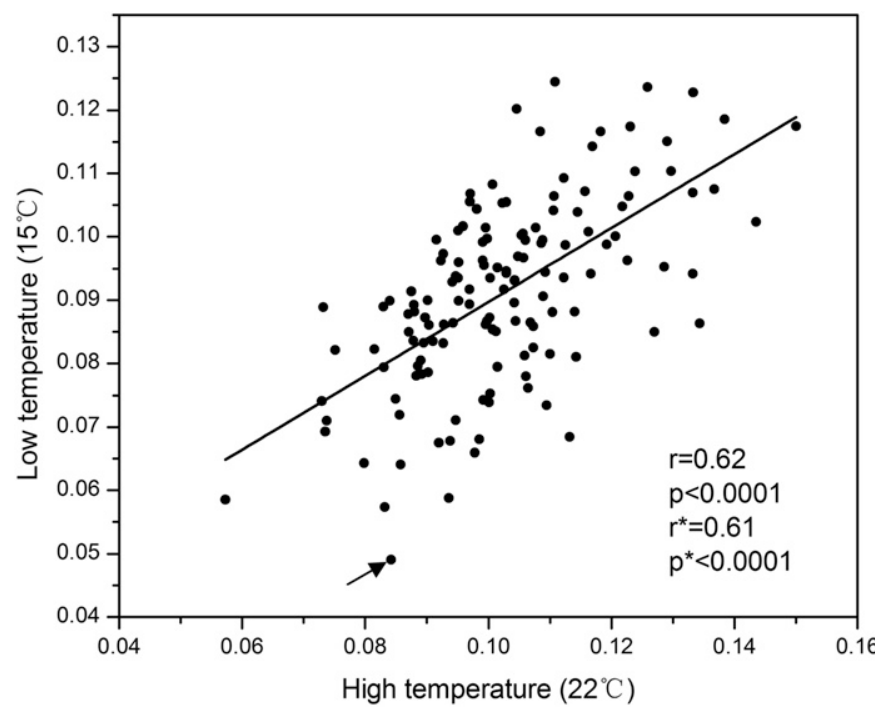

Fig. 5. Correlation of in vitro growth rates for 141 Zymoseptoria tritici isolates cultured under high temperature $\left(22^{\circ} \mathrm{C}\right)$ and low temperature $\left(15^{\circ} \mathrm{C}\right)$. An outlier is marked by an arrow. Correlation coefficients and associated $P$ values after removing the outlier are marked by asterisks. loci (QTL) mapping population using different wheat cultivars (Stewart and McDonald 2014). The isolates included in this study were sampled from several geographically distant locations. Both previous analyses (Yang et al. 2013; Zhan and McDonald 2011; Zhan et al. 2007b) and the current findings of significant isolate-cultivar and isolate-temperature interactions (Table 1) indicated that these isolates vary tremendously in thermal sensitivity, aggressiveness, and metabolic rates among locations, which could contribute to the moderate associations found in this study.

PLACP has been considered to be a more reliable measurement of $Z$. tritici aggressiveness compared with PLACL because the presence of pycnidia is the unequivocal indication of STB disease on wheat (Suffert et al. 2013). It is traditionally believed that PLACL is a more useful measurement of pathogen aggressiveness because it is easier to assess visually and, therefore, more convenient to measure (Brown et al. 2001; Czembor et al. 2011; Suffert et al. 2013) as well as being highly relevant to yield loss. In addition, some STB lesions produce no pycnidia, making the measurement of PLACP
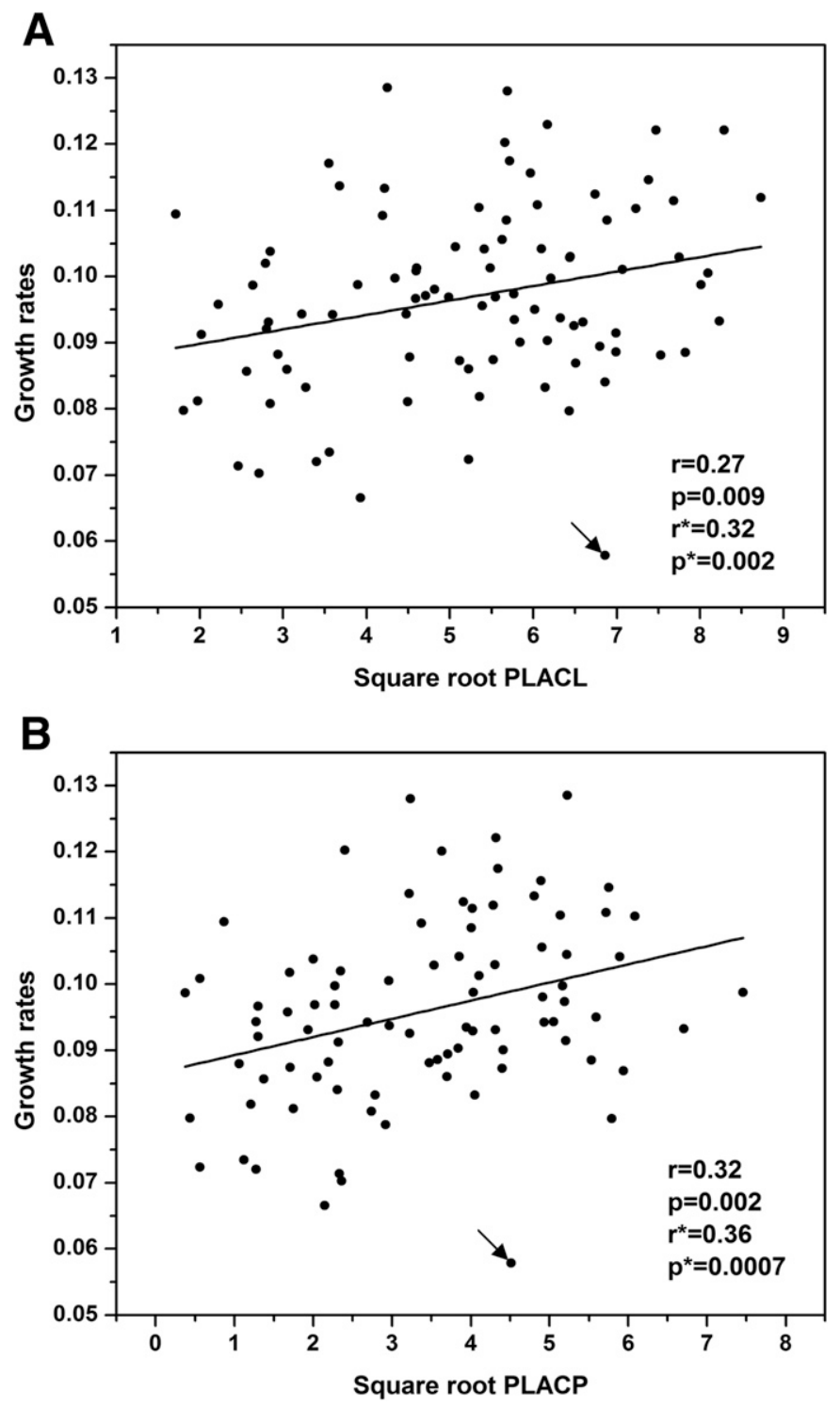

Fig. 6. Correlation between average of in vitro growth rates at two temperatures $\left(15\right.$ and $22^{\circ} \mathrm{C}$ ) and average of aggressiveness measured on two wheat cultivars for 141 Zymoseptoria tritici isolates. Outliers are marked by arrows. Correlation coefficients and associated $P$ values after removing outliers are marked by asterisks. A, Average of percentage of leaf area covered by lesions (PLACL) induced on Toronit and Greina and $\mathbf{B}$, average of percentage of leaf area covered by pycnidia (PLACP) induced on Toronit and Greina. 
impossible. However, this situation is likely to change in the future as techniques for measuring pycnidial density based on analysis of digital images (Stewart and McDonald 2014) are improved. For evolutionary studies oriented around competition and fitness, PLACP may be a preferable measure of aggressiveness for $Z$. tritici (Zhan et al. 2005) and other pathogens (Kim et al. 2005; Kurt and Tok 2006) because it is a more direct measure of pathogen reproduction and fitness.

Though some outliers were found in our datasets, our analysis showed a positive and significant correlation between aggressiveness (both in PLACL and PLACP) and in vitro growth rate of $Z$. tritici isolates (Fig. 6), indicating that, on average, Z. tritici isolates growing faster on petri dishes induce more disease on wheat in planta. Pearson's correlation is known to be sensitive to deviations from a normal distribution, and is especially sensitive to outliers (Ott 1992). When we removed strains exhibiting outlier phenotypes from the analysis, Pearson's correlations between strain aggressiveness and in vitro growth rate increased (Fig. 6), suggesting that the observed association is not due to data artifacts. This finding suggests that in vitro growth rates make an important contribution to overall aggressiveness in $Z$. tritici. This phenomenon may reflect pleiotropic effects of a set of genes that contribute to both aggressiveness and growth rate (Zhan et al. 1998, 2003). The outcomes of QTL mapping experiments indicate that pleiotropy is common in the wheat-Z. tritici system (Lendenmann et al. 2014, 2015, 2016). Fastergrowing isolates may possess alleles that encode a higher level of metabolic activity that enables them to gain a competitive edge in the mixed infections that occur often in the field environment (Linde et al. 2002), thus favoring the emergence of strains with an increased ability to damage host plants in agroecosystems.

\section{ACKNOWLEDGMENTS}

The project was partially supported by Ministry of Science and Technology of China "973" Initiative Grant 2014CB160315 and the Swiss Federal Institute of Technology Grant TH-49a/02-1 We thank D. Croll for analyzing the effects of population structure on the correlations.

\section{LITERATURE CITED}

Ahmed, H. U., Mundt, C. C., Hoffer, M. E., and Coakley, S. M. 1996. Selective influence of wheat cultivars on pathogenicity of Mycosphaerella graminicola (anamorph Septoria tritici). Phytopathology 86:454-458.

Alker, A. P., Smith, G. W., and Kim, K. 2001. Characterization of Aspergillus sydowii (Thom et Church), a fungal pathogen of Caribbean sea fan corals. Hydrobiologia 460:105-111.

Allioui, N., Siah, A., Brinis, L., Reignault, P., and Halama, P. 2014. Mating type distribution provides evidence for sexual reproduction of Mycosphaerella graminicola in Algeria. Can. J. Plant Pathol. 36:475-481.

Antal, Zs., Manczinger, L., Szakacs, Gy., Tengerdy, R. P., and Ferenczy, L. 2000. Colony growth, intrinsic antagonism and secretion of extracellular enzymes in cold-tolerant strains of Trichoderma species. Mycol. Res. 104: 545-549.

Bari, R., and Jones, J. D. G. 2009. Role of plant hormones in plant defence responses. Plant Mol. Biol. 69:473-488.

Bates, D. M., and Watts, D. G. 1988. Nonlinear Regression Analysis and its Applications. John Wiley and Sons, Inc., New York.

Belisario, B. A., Scotton, M., Santori, A., and Onofri, S. 2008. Variability in the Italian population of Gnomonia leptostyla, homothallism and resistance of Juglans species to anthracnose. For. Pathol. 38:129-145.

Blomberg, A. 2011. Measuring growth rate in high-throughput growth phenotyping. Curr. Opin. Biotechnol. 22:94-102.

Brasier, C. M., and Webber, J. F. 1987. Positive correlations between intrinsic growth rate and pathogenesis in Ophiostoma ulmi. Plant Pathol. 36:462466.

Brennan, J. M., Fagan, B., van Maanen, A., Cooke, B. M., and Doohan, F. M. 2003. Studies on intrinsic growth and pathogenicity of European Fusarium fungi. Eur. J. Plant Pathol. 109:577-587.

Brown, J. K. M., Kema, G. H. J., Forrer, H. R., Verstappen, E. C. P., Arraiano, L. S., Brading, P. A., Foster, E. M., Fried, P. M., and Jenny, E. 2001. Resistance of wheat cultivars and breeding lines to Septoria tritici blotch caused by isolates of Mycosphaerella graminicola in field trials. Plant Pathol. 50:325-338.
Caffier, V., Didelot, F., Pumo, B., Causeur, D., Durel, C. E., and Parisi, L. 2010. Aggressiveness of eight Venturia inaequalis isolates virulent or avirulent to the major resistance gene Rvi6 on a non-Rvi6 apple cultivar. Plant Pathol. 59:1072-1080.

Chartrain, L., Brading, P. A., Makepeace, J. C., and Brown, J. K. M. 2004a. Sources of resistance to septoria tritici blotch and implications for wheat breeding. Plant Pathol. 53:454-460.

Chartrain, L., Brading, P. A., Widdowson, J. P., and Brown, J. K. M. 2004b. Partial resistance to Septoria Tritici Blotch (Mycosphaerella graminicola) in wheat cultivars Arina and Riband. Phytopathology 94:497-504.

Chotivanich, K., Udomsangpetch, R., Simpson, J. A., Newton, P., Pukrittayakamee, S., Looareesuwan, S., and White, N. J. 2000. Parasite multiplication potential and the severity of falciparum malaria. J. Infect. Dis. 181:1206-1209.

Cowger, C., and Mundt, C. C. 2002. Aggressiveness of Mycosphaerella graminicola isolates from susceptible and partially resistant wheat cultivars. Phytopathology 92:624-630.

Czembor, P. C., Radecka-Janusik, M., and Mankowski, D. 2011. Virulence spectrum of Mycosphaerella graminicola isolates on wheat genotypes carrying known resistance genes to Septoria tritici Blotch. J. Phytopathol. 159:146154 .

Dangl, J. L., and Jones, J. D. G. 2001. Plant pathogens and integrated defence responses to infection. Nature 411:826-833.

Deans, A. M., Lyke, K. E., Thera, M. A., Plowe, C. V., Koné, A., Doumbo, O. K., Kai, O., Marsh, K., Mackinnon, M. J., Raza, A., and Rowe, J. A. 2006. Low multiplication rates of African Plasmodium falciparum isolates and lack of association of multiplication rate and red blood cell selectivity with malaria virulence. Am. J. Trop. Med. Hyg. 74:554-63.

do Amaral, A. M., Antoniw, J., Rudd, J. J., and Hammond-Kosack, K. E. 2012. Defining the predicted protein secretome of the fungal wheat leaf pathogen Mycosphaerella graminicola. PLoS One 7:e49904.

Gomez, K. A., and Gomez, A. A. 1976. Statistical Procedures for Agriculture Research with Emphasis on Rice. International Rice Research Institute, Manila, Philippines.

Goodwin, S. B., M'Barek, S. B., Dhillon, B., Wittenberg, A. H. J., Crane, C. F., Hane, J. K., Foster, A. J., Van der Lee, T. A. J., Grimwood, J., Aerts, A., Antoniw, J., Bailey, A., Bluhm, B., Bowler, J., Bristow, J., van der Burgt, A., Canto-Canché, B., Churchill, A. C. L., Conde-Ferràez, L., Cools, H. J., Coutinho, P. M., Csukai, M., Dehal, P., De Wit, P., Donzelli, B., van de Geest, H. C., van Ham, R. C. H. J., Hammond-Kosack, K. E., Henrissat, B., Kilian, A., Kobayashi, A. K., Koopmann, E., Kourmpetis, Y., Kuzniar, A., Lindquist, E., Lombard, V., Maliepaard, C., Martins, N., Mehrabi, R., Nap, J. P. H., Ponomarenko, A., Rudd, J. J., Salamov, A., Schmutz, J., Schouten, H. J., Shapiro, H., Stergiopoulos, I., Torriani, S. F. F., Tu, H., de Vries, R. P., Waalwijk, C., Ware, S. B., Wiebenga, A., Zwiers, L.-H., Oliver, R. P., Grigoriev, I. V., and Kema, G. H. J. 2011. Finished genome of the fungal wheat pathogen Mycosphaerella graminicola reveals dispensome structure, chromosome plasticity, and stealth pathogenesis. PLoS Genet. 7:e1002070.

Hu, K. M., Qiu, D. Y., Shen, X. L., Li, X. H., and Wang, S. P. 2008. Isolation and manipulation of quantitative trait loci for disease resistance in rice using a candidate gene approach. Mol. Plant 1:786-793.

Irzykowska, L., and Bocianowski, J. 2008. Genetic variation, pathogenicity and mycelial growth rate differentiation between Gaeumannomyces graminis var. tritici isolates derived from winter and spring wheat. Ann. Appl. Biol. 152:369-375.

Irzykowska, L., Wolko, B., and Swiecicki, W. K. 2001. The genetic linkage map of pea (Pisum sativum L.) based on molecular, biochemical and morphological markers. Pisum Genet. 33:13-18.

Jorgensen, L. N., Hovmoller, M. S., Hansen, J. G., Lassen, P., Clark, B., Bayles, R., Rodemann, B., Flath, K., Jahn, M., Goral, T., Czembor, J. J., Cheyron, P., Maumene, C., De Pope, C., Ban, R., Nielsen, G. C., and Berg, G. 2014. IPM strategies and their dilemmas including an introduction to www.eurowheat.org. J. Integr. Agric. 13:265-281.

Kelm, C., Tabib Ghaffary, S. M., Bruelheide, H., Roder, M. S., Miersch, S., Weber, W. E., Kema, G. H. J., and Saal, B. 2012. The genetic architecture of seedling resistance to Septoria tritici blotch in the winter wheat doubledhaploid population Solitar $\times$ Mazurka. Mol. Breed. 29:813-830.

Kema, G. H. J., Aoonoe, J. G., Sayoud, R., Van Silfhout, C. H., Van Ginkel, M., and de Bee, J. 1996. Genetic variation for virulence and resistance in the wheat-Mycosphaerella graminicola pathosystem I: Interactions between pathogen isolates and host cultivars. Phytopathology 86:200-212.

Kim, Y. K., Xiao, C. L., and Rogers, J. D. 2005. Influence of culture media and environmental factors on mycelial growth and pycnidial production of Sphaeropsis pyriputrescens. Mycologia 97:25-32.

Krenz, J. E., Sackett, K. E., and Mundt, C. C. 2008. Specificity of incomplete resistance to Mycosphaerella graminicola in wheat. Phytopathology 98:555-561.

Kurt, S., and Tok, F. M. 2006. Influence of inoculum concentration, leaf age, temperature, and duration of leaf wetness on Septoria blight of parsley. Crop Prot. 25:556-561. 
Lamari, L. 2002. Assess: Image Analysis Software for Plant Disease Quantification. American Phytopathological Society, St. Paul, MN.

Lannou, C. 2012. Variation and selection of quantitative traits in plant pathogens. Annu. Rev. Phytopathol. 50:319-338.

Lee, D. H., Roux, J., Wingfield, B. D., and Wingfield, M. J. 2015. Variation in growth rates and aggressiveness of naturally occurring self-fertile and selfsterile isolates of the wilt pathogen Ceratocystis albifundus. Plant Pathol. 64:1103-1109.

Lendenmann, M. H., Croll, D., and McDonald, B. A. 2015. QTL mapping of fungicide sensitivity reveals novel genes and pleiotropy with melanization in the pathogen Zymoseptoria tritici. Fungal Genet. Biol. 80:53-67.

Lendenmann, M. H., Croll, D., Palma-Guerrero, J., Stewart, E. L., and McDonald, B. A.2016. QTL mapping of temperature sensitivity reveals candidate genes for thermal adaptation and growth morphology in the plant pathogenic fungus Zymoseptoria tritici. Heredity 116:384-394.

Lendenmann, M. H., Croll, D., Stewart, E. L., and McDonald, B. A. 2014. Quantitative trait locus mapping of melanization in the plant pathogenic fungus Zymoseptoria tritici. G3: Genes Genomes Genet. 4:2519-2533.

Li, S., Hartman, G. L., and Chen, Y. 2009. Evaluation of aggressiveness of Fusarium virguliforme isolates that cause soybean sudden death syndrome. J. Plant Pathol. 91:77-86.

Linde, C. C., Zhan, J., and McDonald, B. A. 2002. Population structure of Mycosphaerella graminicola: From lesions to continents. Phytopathology 92:946-955.

Lozoya-Saldaña, H. 2011. Evolution of vertical and horizontal resistance and its application in breeding resistance to potato late blight. Potato J. 38:1-8.

Makhdoomi, A., Mehrabi, R., Khodarahmi, M., and Abrinbana, M. 2015. Efficacy of wheat genotypes and Stb resistance genes against Iranian isolates of Zymoseptoria tritici. J. Gen. Plant Pathol. 81:5-14

Malbrán, I., Mourelos, C. A., Girotti, J. R., Aulicino, M. B., Balatti, P. A., and Lori, G. A. 2012. Aggressiveness variation of Fusarium graminearum isolates from Argentina following point inoculation of field grown wheat spikes. Crop Prot. 42:234-243.

Marcel, T. C., Gorguet, B., Ta, M. T., Kohutova, Z., Vels, A., and Niks, R. E. 2008. Isolate specificity of quantitative trait loci for partial resistance of barley to Puccinia hordei confirmed in mapping populations and near isogenic lines. New Phytol. 177:743-755.

McConnell, M. J., Docobo-Pérez, F., Mata, R. C., Fernandez-Cuenca, F., Viciana, P., López-Cortés, L. F., Trastoy, M., Pachón, J., and Pérez-Romero, P. 2008. Molecular epidemiology of HIV Type 1 in newly diagnosed patients in southern Spain. AIDS Res. Hum. Retroviruses 24:881-887.

Meyer, S. E., Stewart, T. E., and Clement, S. 2010. The quick and the deadly: Growth vs virulence in a seed bank pathogen. New Phytol. 187:209-216.

Montarry, J., Cartolaro, P., Delmotte, F., Jolivet, J., and Willocquet, L. 2008. Genetic structure and aggressiveness of Erysiphe necator populations during grapevine powdery mildew epidemics. Appl. Environ. Microbiol. 74: 6327-6332.

Montarry, J., Corbiere, R., Lesueur, S., Glais, I., and Andrivon, D. 2006. Does selection by resistant hosts trigger local adaptation in plant-pathogen systems? J. Evol. Biol. 19:522-531.

Morais, D., Sache, I., Suffert, F., and Laval, V. 2016. Is the onset of Septoria tritici blotch epidemics related to the local pool of ascospores? Plant Pathol. 65:250-260

Mundt, C. C., Brophy, L. S., and Schmitt, M. S. 1995. Choosing crop cultivars and cultivar mixtures under low versus high disease pressure: A case study with wheat. Crop Prot. 14:509-515.

Mundt, C. C., Cowger, C., and Garrett, K. A. 2002. Relevance of integrated disease management to resistance durability. Euphytica 124:245-252.

Novo, M., Pomar, F., Gayoso, C., and Merino, F. 2006. Cellulase activity in isolates of Verticillium dahliae differing in aggressiveness. Plant Dis. 90:155-160.

O'Driscoll, A., Kildea, S., Doohan, F., Spink, J., and Mullins, E. 2014. The wheat-Septoria conflict: A new front opening up? Trends Plant Sci. 19: 602-610.

Ott, R. L. 1992. An Introduction to Statistical Methods and Data Analysis, 4th ed. Duxbury Press, Belmont, USA.

Pariaud, B., Goyeau, H., and Halkett, F. 2012. Variation in aggressiveness is detected among Puccinia triticina isolates of the same pathotype and clonal lineage in the adult plant stage. Eur. J. Plant Pathol. 134:733-743.

Pariaud, B., Robert, C., Goyeau, H., and Lannou, C. 2009. Aggressiveness components and adaptation to a host cultivar in wheat leaf rust. Phytopathology 99:869-878.

Poland, J. A., Balint-Kurti, P. J., Wisser, R. J., Pratt, R. C., and Nelson, R. J. 2009. Shades of gray: The world of quantitative disease resistance. Trends Plant Sci. 14:21-29.

Pringle, A., and Taylor, J. W. 2002. The fitness of filamentous fungi. Trends Microbiol. 10:474-481.
Radecka-Janusik, M., and Czembor, P. C. 2014. Genetic mapping of quantitative trait loci (QTL) for resistance to Septoria tritici blotch in a winter wheat cultivar Liwilla. Euphytica 200:109-125.

SAS Institute Inc. 1990. SAS User's Guide to Statistics, Version 6. 4th ed. SAS Institute Inc., Cary, NC.

Shaw, M. W., and Royle, D. J. 1989. Airborne inoculum as a major source of Septoria tritici (Mycosphaerella graminicola) infections in winter wheat crops in the UK. Plant Pathol. 38:35-43.

Sidhu, Y. S., Chaudhari, Y. K., Usher, J., Cairns, T. C., Csukai, M., and Haynes, K. 2015. A suite of gateway compatible ternary expression vectors for functional analysis in Zymoseptoria tritici. Fungal Genet. Biol. 79:180-185.

Sokurenko, E. V., Hasty, D. L., and Dykhuizen, D. E. 1999. Pathoadaptive mutations: Gene loss and variation in bacterial pathogens. Trends Microbiol. 7:191-195

Stewart, E. L., and McDonald, B. A. 2014. Measuring quantitative virulence in the wheat pathogen Zymoseptoria tritici using high-throughput automated image analysis. Plant Pathol. 104:985-992.

Suffert, F., Sache, I., and Lannou, C. 2013. Assessment of quantitative traits of aggressiveness in Mycosphaerella graminicola on adult wheat plants. Plant Pathol. 62:1330-1341

Talas, F., Kalih, R., Miedaner, T., and McDonald, B. A. 2016. Genome-wide association study identifies novel candidate genes for aggressiveness, deoxynivalenol production and azole sensitivity in field populations of Fusarium graminearum. Mol. Plant-Microbe Interact. 29:417-430.

Thrall, P. H., Barrett, L. G., Burdon, J. J., and Alexander, H. M. 2005. Variation in pathogen aggressiveness within a metapopulation of the Cakile maritime-Alternaria brassicicola host-pathogen association. Plant Pathol. $54: 265-274$

Weber, Z., Irzykowska, L., and Bocianowski, J. 2005. Analysis of mycelial growth rates and RAPD-PCR profiles in a population of Gaeumannomyces graminis var. tritici originating from wheat plants grown from fungicidetreated seed. J. Phytopathol. 153:318-324.

Yang, L., Gao, F., Shang, L., Zhan, J., and McDonald, B. A. 2013. Association between virulence and triazole tolerance in the phytopathogenic fungus Mycosphaerella graminicola. PLoS One 8:e59568.

Zadoks, J. C., Chang, T. T., and Konzak, C. F. 1974. Decimal code for growth stages of cereals. Weed Res. 14:415-421.

Zhan, J., Linde, C. C., Jurgens, T., Merz, U., Steinebrunner, F., and McDonald, B. A. 2005. Variation for neutral markers is correlated with variation for quantitative traits in the plant pathogenic fungus Mycosphaerella graminicola. Mol. Ecol. 14:2683-2693.

Zhan, J., and McDonald, B. A. 2005. Analytical and experimental methods for estimating population genetic structure of fungi. Pages 241-263 in: The Fungal Community: Its Organization and Role in the Ecosystem. J. Dighton, P. Oudemans, and J. White, eds. CRC Press, Cleveland, OH.

Zhan, J., and McDonald, B. A. 2011. Thermal adaptation in the fungal pathogen Mycosphaerella graminicola. Mol. Ecol. 20:1689-1701.

Zhan, J., and McDonald, B. A. 2013. Experimental measures of pathogen competition and relative fitness. Annu. Rev. Phytopathol. 51:131-153.

Zhan, J., Mundt, C. C., Hoffer, M. E., and McDonald, B. A. 2002. Local adaptation and effect of host genotype on the rate of pathogen evolution: An experimental test in a plant pathosystem. J. Evol. Biol. 15:634-647.

Zhan, J., Mundt, C. C., and McDonald, B. A. 1998. Measuring immigration and sexual reproduction in field populations of Mycosphaerella graminicola. Phytopathology 88:1330-1337.

Zhan, J., Mundt, C. C., and McDonald, B. A. 2007a. Sexual reproduction facilitates the adaptation of parasites to antagonistic host environments: Evidence from empirical study in the wheat-Mycosphaerella graminicola system. Int. J. Parasitol. 37:861-870.

Zhan, J., Pettway, R. E., and McDonald, B. A. 2003. The global genetic structure of the wheat pathogen Mycosphaerella graminicola is characterized by high nuclear diversity, low mitochondrial diversity, regular recombination, and gene flow. Fungal Genet. Biol. 38:286-297.

Zhan, J., Thrall, P. H., and Burdon, J. J. 2014. Achieving sustainable plant disease management through evolutionary principles. Trends Plant Sci. 19: $570-575$

Zhan, J., Thrall, P. H., Papaïx, J., Xie, L., and Burdon, J. J. 2015. Playing on a pathogen's weakness: Using evolution to guide sustainable plant disease control strategies. Annu. Rev. Phytopathol. 53:19-43.

Zhan, J., Torriani, S. F. F., and McDonald, B. A. 2007b. Significant difference in pathogenicity between MAT1-1 and MAT1-2 isolates in the wheat pathogen Mycosphaerella graminicola. Fungal Genet. Biol. 44:339-346.

Zhu, W., Yang, L. N., Wu, E. J., Qin, C. F., Shang, L. P., Wang, Z. H., and Zhan, J. 2015. Limited sexual reproduction and quick turnover in the population genetic structure of Phytophthora infestans in Fujian, China. Sci. Rep. 5:Article number 10094. doi:10.1038/srep10094 